\title{
Recursos Educacionais Abertos para o Curso de Ciências Biológicas do Consórcio Cederj: Produção, Uso e Disponibilização
}

\author{
Samira Pirola Santos Mantilla*1, Carmem Adilia Simões da Fonseca², Nathalia \\ Costa Alves ${ }^{3}$, Luciana Tavares Perdigão ${ }^{4}$, Daniel Fábio Salvador ${ }^{5}$
}

\footnotetext{
${ }^{1}$ Designer Instrucional e Pesquisadora, Departamento de Mídias Digitais/Fundação Cecierj. Rua da Ajuda, $\mathrm{n}^{\circ} 5,1^{\circ}$ andar, Centro - Rio de Janeiro - RJ - Brasil. smantilla@cecierj.edu.br

2 Coordenadora de TAPs e Tutora a distância do curso de Ciências Biológicas, Departamento de Mídias Digitais/Fundação Cecierj. Rua da Ajuda, $\mathrm{n}^{\circ} 5,1^{\circ}$ andar, Centro - Rio de Janeiro - RJ, Brasil. carmemad@gmail.com

${ }^{3}$ Designer Instrucional e Pesquisadora, Departamento de Mídias Digitais/Fundação Cecierj. Rua da Ajuda, $\mathrm{n}^{\circ}$ 5, $15^{\circ}$ andar, Centro - Rio de Janeiro - RJ - Brasil. nalves@cecierj.edu.br

${ }^{4}$ Designer Instrucional e Pesquisadora, Departamento de Mídias Digitais/Fundação Cecierj. Rua da Ajuda, $\mathrm{n}^{\circ}$ 5, $15^{\circ}$ andar, Centro - Rio de Janeiro - RJ - Brasil. Iperdigao@cecierj.edu.br

5 Professor e Pesquisador, Departamento de Mídias Digitais/Fundação Cecierj. Rua da Ajuda, $\mathrm{n}^{\circ} 5,5^{\circ}$ andar, Centro - Rio de Janeiro - RJ - Brasil. salvador@cecierj.edu.br
}

\section{Resumo}

Este trabalho visa descrever e fazer uma reflexão sobre o processo de produção e uso de Recursos Educacionais Abertos (REAs) no curso semipresencial de Ciências Biológicas do Consórcio Cederj em uma perspectiva evolutiva histórica, inicialmente mais focado na produção intensiva de REAs e posteriormente no maior apoio aos docentes para seleção e uso desses recursos disponíveis na web. Para isso, foi feito um levantamento da quantidade de REAs produzidos e disponibilizados para os alunos desde 2003 até 2013 e também uma análise do seu uso para todas as disciplinas no ambiente de aprendizagem virtual do curso. Verificou-se que houve uma mudança de paradigma do uso, produção e disponibilização de REAs para a sala de aula virtual, que se traduziu em benefício de enriquecimento quantitativo de recursos multimídias para os alunos, visto que de 2012 a 2013 houve um aumento de 63\% da disponibilização de REAs nas disciplinas.

Palavras-chave: REAs; Ciências Biológicas; Ambiente virtual de aprendizagem; Moodle. 


\title{
Open Educational Resources for the Course of Biological Sciences at the Cederj Consotium: Production, Use and Availability
}

\begin{abstract}
This paper aims to describe and to reflect on the process of production and use of Open Educational Resources (OER) in the Biology undergraduate program of the Consórcio Cederj in a historical evolutionary perspective, initially focused on intensive production of OER and later on giving support to teachers for the selection and use of these resources available on the web. A survey was made to discover the amount of OER produced and made available to students from 2003 to 2013 . There was also a review of its use for all subjects in a virtual learning environment (VLE) of the biological sciences course. It was found that there was a paradigm change of the use, production, and availability of OER in the virtual learning environment that resulted in favor of quantitative enrichment of multimedia resources for students. From 2012 to 2013 there was an increase of $63 \%$ of availability of OER in the subjects.
\end{abstract}

Keywords: OER; Biology; VLE; Moodle. 


\section{Introdução}

Os Recursos Educacionais Abertos (REAs) produzidos pela Fundação Cecierj para o curso de graduação a distância em Ciências Biológicas vêm sofrendo uma mudança significativa nos últimos anos na sua forma de uso e incorporação às salas de aulas virtuais. O modelo de EaD do Cederj para esse curso era composto basicamente por material impresso e webaulas (animações em flash) em sala de aula pouco colaborativa e amigável à autoria do professor. No ano de 2012, foi implementada a plataforma Moodle (Modular Object - Oriented Dynamic Learning Environment), com uma nova cultura de autoria do professor para uso da sala de aula, o que afetou a utilização de recursos multimídias nesse curso. Os professores foram estimulados a buscar REAs disponíveis na web, para complementar as aulas, e poderiam solicitar para a equipe de produção a elaboração de um REA que considerasse essencial para a disciplina.

O objetivo dessa pesquisa foi analisar o processo de produção, utilização e disponibilização de REAs do curso de graduação em Ciências Biológicas do Consórcio Cederj nessa perspectiva histórica.

\subsection{Recursos Educacionais Abertos (REAs) e repositórios web}

Recursos Educacionais Abertos (REAs) são definidos pela Unesco (2002) como recursos educacionais tecnológicos abertos para uso, consulta e adaptação por uma comunidade de usuários com fins não comerciais. Esses recursos são, normalmente, disponibilizados gratuitamente na web e incluem objetos de aprendizagem, tais como material de aula, textos, simulações, experiências e demonstrações, bem como guias dos professores (UNESCO, 2002).

De acordo com Laaser, Rodrigues e Fachin (2009), o conteúdo aberto teve sua evolução a partir dos anos 90 com iniciativas das comunidades virtuais e o uso de plataformas abertas. Essa iniciativa permite o acesso a conteúdos educacionais já existentes como artigo, imagem, áudio e vídeo e se apresentam em formato que permite sua reprodução. Esse conteúdo aberto constitui-se em arquivo compartilhado que pode ser livremente reutilizado, possibilitando a autoria coletiva e cooperativa. Segundo Okada e Barros (2010), o crescimento de REAs tem propiciado a participação 
cada vez maior de instituições de diferentes países que estão divulgando suas produções na web, favorecendo uma grande quantidade de usuários da web.

Ferreira et al. (2013) salientam que nas instituições públicas de ensino o caminho natural é disponibilizar os recursos educacionais de forma aberta, visto que muitas vezes são recursos que exigiram muito tempo e esforço na sua elaboração. Assim, um número maior de pessoas poderá fazer uso e reuso dos mesmos com o objetivo de ensino, aprendizagem e pesquisa.

Segundo Silva, Café e Catapan (2010), os objetos de aprendizagem devem ser criados com as seguintes características: acessibilidade (devem possuir uma identificação padronizada que garanta a sua recuperação); reusabilidade (devem ser desenvolvidos de forma a compor diversas unidades de aprendizagem); interoperabilidade (devem ser criados para serem operados em diferentes plataformas e sistemas); portabilidade (devem ser criados com a possibilidade de se mover e se abrigar em diferentes plataformas); durabilidade (devem permanecer intactos perante as atualizações de software ou hardware). E, de acordo com Ferreira (2013), para que um item seja considerado um REA, ele precisa apresentar as seguintes características: ser digital, reutilizável, acessível, interoperável, durável, portável e expressar autoria.

A reutilização dos REAs é uma das principais características desses recursos e diminui os gastos com a produção de recursos multimídias pelas instituições de ensino que podem modificá-los de acordo com suas necessidades. Teixeira (2012) ressalta que a utilização, reutilização, edição e adaptação de REAs, nos mais diversos contextos, tornaram-se algo bastante simples, legal, seguro e confiável e acrescenta que o seu uso poderia proporcionar uma aprendizagem massificada de modo mais econômico e rápido.

Do ponto de vista acadêmico, os REAs são reconhecidos como objetos desenhados com um valor educativo e uma estrutura pedagógica, desenvolvidos em ambientes abertos por uma ampla comunidade de educadores, o que permite mais facilmente aperfeiçoá-los e adaptá-los. É por essa razão que os REAs têm sido vistos como promotores de inovações educativas, favorecendo a introdução de novas formas de ensino e aprendizagem (Teixeira, 2012). 
Os REAS podem ser inseridos ou até mesmo integrados em Ambientes Virtuais de Aprendizagem (AVA) para facilitar o uso desses objetos de aprendizagem pelos alunos, visto que os mesmos estarão contextualizados dentro das aulas da disciplina. De acordo com Tauroco et. al. (2013), a integração dos repositórios de objetos de aprendizagem com AVAs tem o objetivo de facilitar o uso dos objetos de aprendizagem por parte dos professores uma vez que o ambiente no qual os professores atuam mais frequentemente é o AVA.

Os REAs são armazenados em bases de dados disponíveis na internet, denominadas de repositórios onde são descritos por meio de metadados. Repositórios são bancos de dados onde REAs são depositados e indexados. Muitos repositórios permitem mais funções, como a própria criação e recombinação de REAs, sendo assim projetos mais complexos.

De acordo com Silva, Café e Catapan (2010), os repositórios de objetos de aprendizagem diferem de bibliotecas especializadas, tendo em vista que a filosofia que norteia o funcionamento desses repositórios é baseada no processo de colaboração e no autoarquivamento, uma vez que todos podem colocar seus objetos e partilhá-los com espírito de comunidade. O uso desses objetos é autorizado pelo próprio autor, podendo ser totalmente aberto ou restrito em algumas situações.

A melhor maneira de se encontrar um objeto de aprendizagem é por intermédio dos repositórios, ou seja, bibliotecas digitais especializadas nesse tipo de recurso. Existem na web diferentes repositórios de REAs que podem ser acessados pelos professores e alunos na busca de objetos de aprendizagem em sua área de atuação. Alguns exemplos de repositórios estrangeiros são ARIADNE, CAREO, MERLOT e nacionais, BIOE, CESTA, RIVED.

A Fundação Cecierj possui um repositório conhecido como Portal Teca/CRV (http://teca.cecierj.edu.br/), criado em março de 2010, e que consiste em um repositório gratuito de material didático desenvolvido para alocar, de forma organizada, objetos de aprendizagem com potencial para enriquecer aulas e trabalhos educacionais. Nesse portal, encontram-se imagens de uso liberado produzidas e/ou cedidas por parceiros sobre os mais diferentes assuntos bem como videoaulas, animações, vídeos, áudios e documentos (Figura 1), produzidos principalmente pelo Consórcio Cederj/Fundação Cecierj assim como aqueles doados por professores 
particulares e/ou de instituições parceiras. Nesse último caso, os professores comprovadamente liberaram o uso dos materiais didáticos quanto aos direitos autorais.

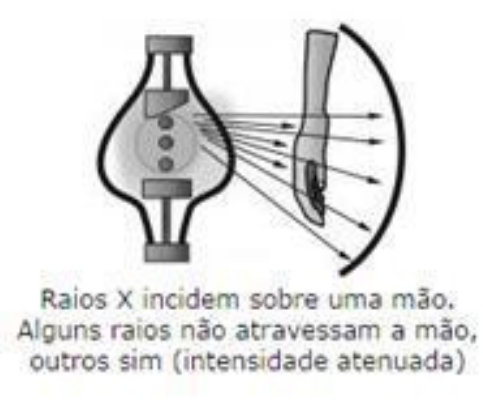

A

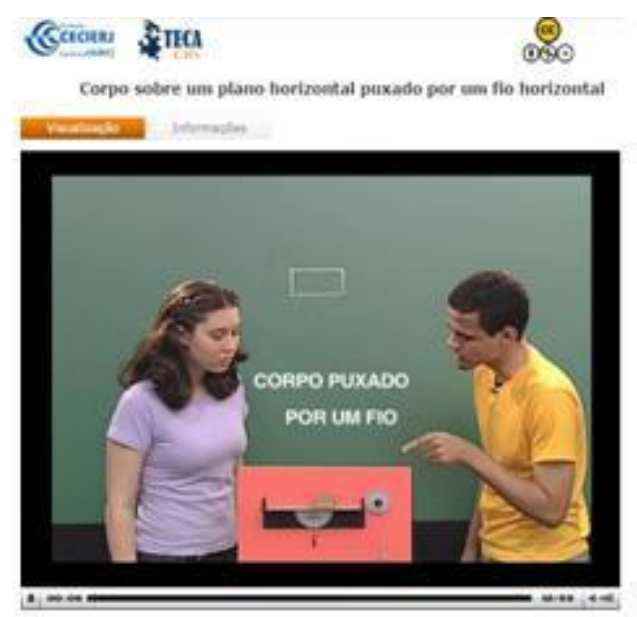

B

Figura 1 - Ilustração (A) e videoaula (B) disponibilizadas no portal TECA.

O uso das mídias do Portal TECA/CRV está regulado pela licença Creative Commons 2.5, com Atribuição - Não Comercial - Sem Derivados (CC BY-NC-ND) e possui acesso liberado para o público em geral.

\section{Metodologia}

A metodologia utilizada nessa pesquisa foi exploratória com a descrição do processo de produção e utilização dos REAs em dois momentos distintos de publicação desses recursos nas salas de aula pelos professores (webaulas e autoria na plataforma Moodle). Para a análise do percentual de uso dos REAs nas disciplinas, foram levantados dados entre os anos de 2003 a 2013 e elaborados tabelas e gráficos permitindo uma análise descritiva. 


\subsection{Modelo webaula}

No modelo inicial de produção de REAs do curso de graduação em Ciências Biológicas do Consórcio Cederj, eram elaboradas webaulas, onde o conteúdo de cada uma das aulas do material impresso das disciplinas era disponibilizado sob a forma de animações interativas em flash (Figura 2). Segundo Benchimol et al. (2010), nesse modelo, por meio de uma navegação linear, o aluno possuía pleno controle do andamento da aula, tendo como estímulos a riqueza visual e a interatividade, permitindo caminhar no seu próprio tempo até a completa compreensão do conteúdo.

No setor de Biologia, foram produzidas, em sete anos (2003 a 2009), 12 disciplinas completas, cada uma delas possuindo em média 20,5 webaulas, com uma média de 287 REAs por disciplina, totalizando 3444 REAs. Esses REAs eram disponibilizados para os alunos em DVD e na web, por meio de acesso restrito, e, ao final de 2012, todo esse montante de recursos foi liberado para uso público no Portal Teca, representando $60,42 \%$ do total de produções do gênero no Consórcio Cederj.

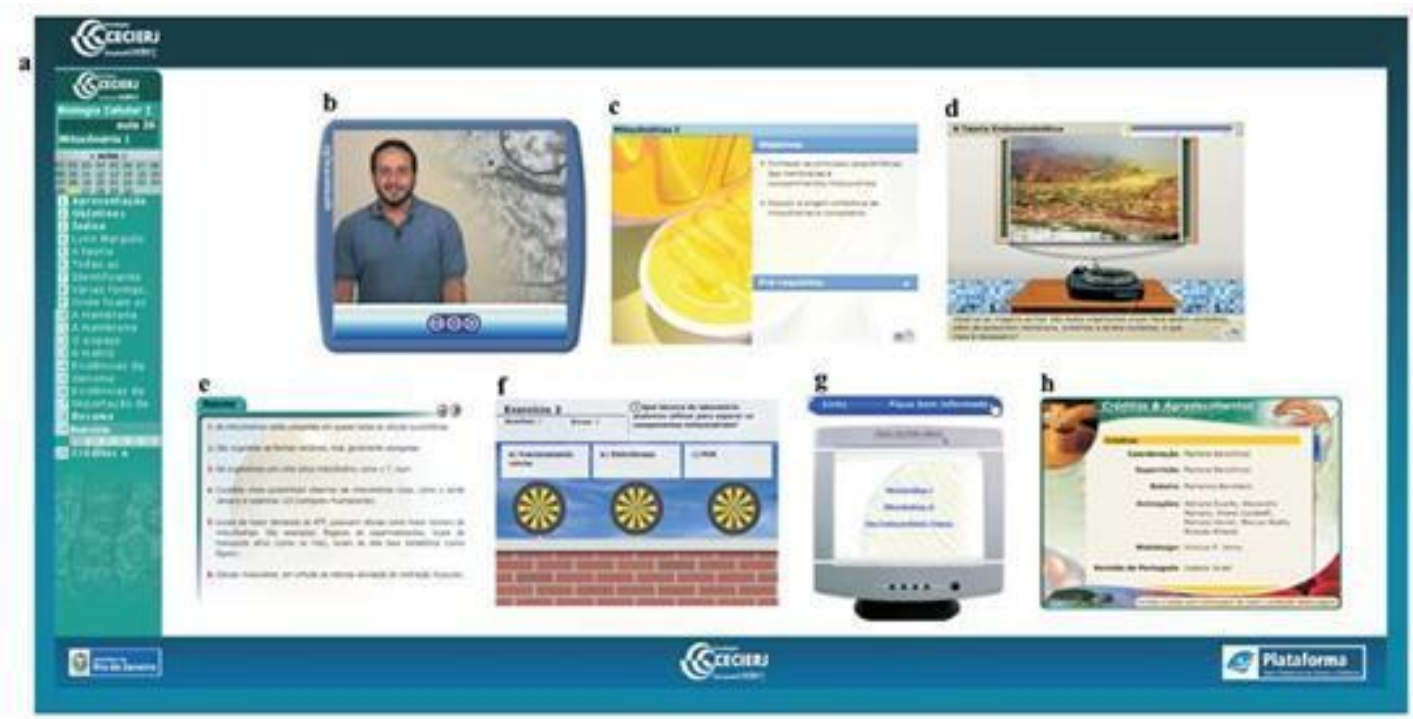

Figura 2 - Exemplo da estrutura de uma webaula. Em (a), barra de navegação da plataforma (ou CD); (b) vídeo de apresentação; (c) objetivos e pré-requisitos; (d) animações de conteúdo das aulas; (e) resumo; (f) página de links externos; (g) exercícios; (h) créditos e agradecimentos. (Fonte: Benchimol et al., 2010). 


\subsection{Autoria do professor na edição da plataforma Moodle}

A partir de 2012, a Fundação Cecierj decidiu modificar sua metodologia de produção e disponibilização de recursos multimídias na web, em favor do estreitamento do contato entre professores especialistas em conteúdo e a equipe de produção, bem como o estímulo à autoria do espaço virtual pelos coordenadores de disciplina, fazendo com que esses professores repensassem a real necessidade da produção de objetos de aprendizagem virtual. Nesse momento, a produção de webaulas foi substituída por produção de objetos de aprendizagem sob demanda para a sala de aula virtual a partir da solicitação para uma determinada disciplina. A produção de REAs passou a ser mais pontual e específica focada em temas de mais difícil compreensão, onde esses objetos de aprendizagem tivessem maior impacto pedagógico.

Além disso, como na educação a distância é importante que os alunos interajam entre si e professores, por exemplo, por meio de fóruns de discussão, estimulando a aprendizagem colaborativa, o espaço da sala de aula virtual das disciplinas desse curso também foi repensado. Foi implantada a plataforma Moodle (Modular Object Oriented Dynamic Learning Environment) com layout customizado, contendo banner, imagens, botões personalizados, sala de tutoria. A plataforma Moodle, por filosofia, é socioconstrutivista com foco na maior autonomia de edição do professor na criação e condução do seu espaço virtual de aprendizagem (Figura 3). 


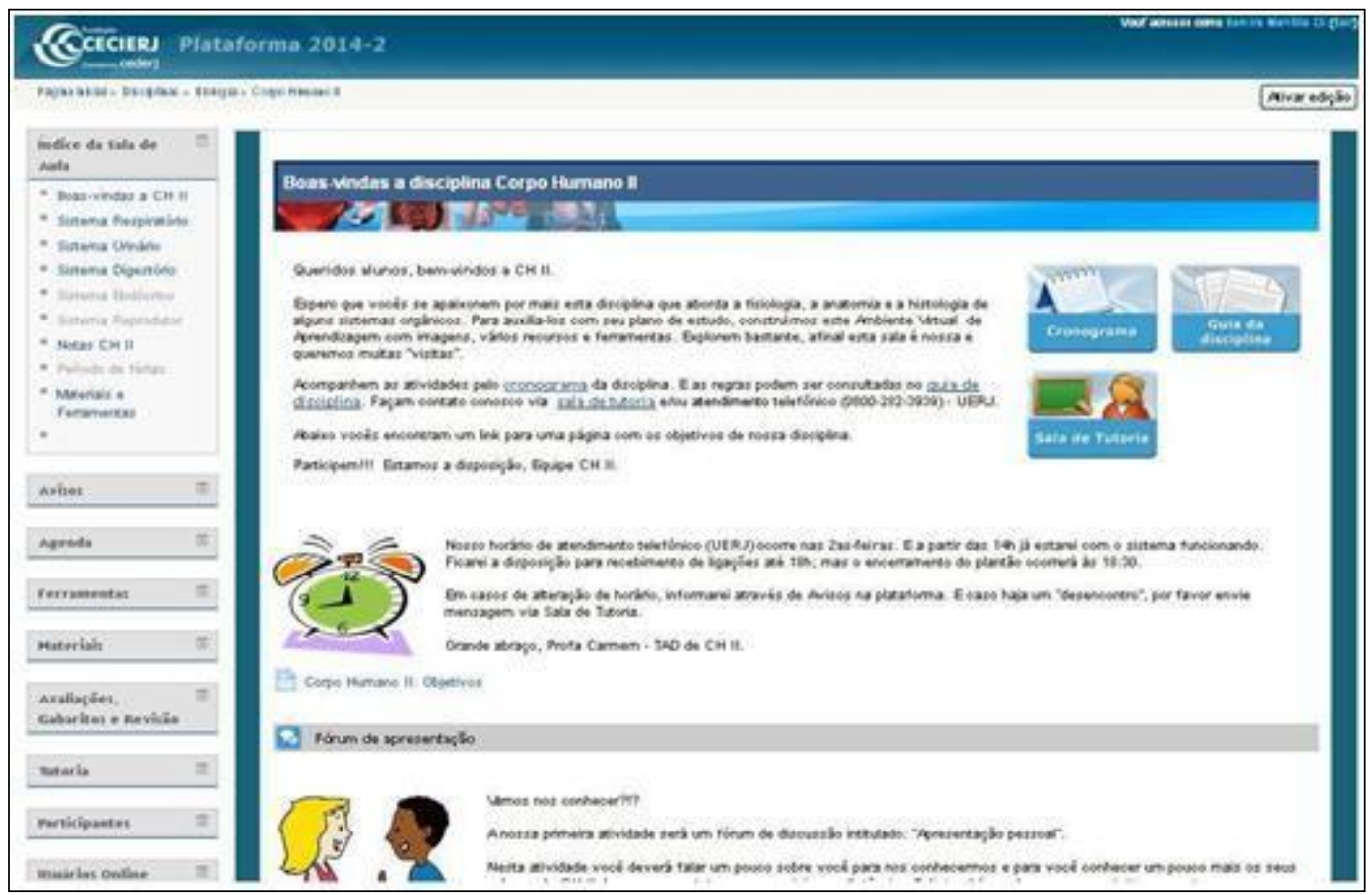

Figura 3 - Exemplo de uma sala de aula na plataforma Moodle.

O Moodle foi criado em 1999 pelo educador e cientista computacional australiano Martin Dougiamas. Atualmente, esse software aberto, livre e gratuito é um dos mais utilizados pelas Instituições de Ensino Superior do Brasil que oferecem cursos a distância e também pode ser utilizado como apoio ao ensino presencial (Carlini; Tarcia, 2010).

A plataforma Moodle é muito utilizada para a construção dos AVAs. Esse software disponibiliza ferramentas que propiciam a comunicação entre os participantes do AVA bem como ferramentas de publicação de conteúdo, além de apresentar ferramentas de gerenciamento das atividades on-line. Em suma, essa plataforma apresenta toda a estrutura administrativa, acadêmica e as ferramentas de interação necessárias para um curso a distância (Delgado et al., 2008).

As principais ferramentas síncronas e assíncronas disponíveis aos usuários no Ambiente Virtual de Aprendizagem (AVA) são: chats, diários, videoaulas, fórum, lista de discussão, correio eletrônico, mural, enquete, portfólio, glossário, questionário, wiki, perfil e FAQ (Frequently Asked Questions). 
Nesse mesmo ano de 2012, o curso passou a ter um Designer Instrucional (DI) e tutores de apoio ao professor (TAPs), responsáveis por capacitar e apoiar os professores na construção da sua sala de aula. Nessa filosofia, os professores tinham total autonomia na edição da sala on-line como, por exemplo, a inclusão de REAs e receberam capacitação para atuarem como editores da plataforma. Durante o ano, eram também oferecidos diversos cursos on-line e oficinas presenciais para capacitação em serviço para uso da plataforma Moodle para coordenadores de disciplina e tutores, visando ao estímulo na autonomia do uso desse espaço virtual.

\section{Resultados e discussão}

Comparando-se os dois modelos de EaD utilizados pela Fundação Cecierj, verifica-se que o modelo anterior, de webaulas, apesar de ser atraente para o aluno e estimular o seu autoaprendizado, demandava muito tempo de produção e dificultava a atualização do conteúdo pelos professores. Já no modelo atual, onde se utiliza a plataforma Moodle, observa-se que o ambiente virtual é facilmente editável pelos professores e possui diferentes ferramentas de comunicação e interação que facilitam o processo de aprendizagem assim como o acesso a diversos REAs selecionados pelo professor da disciplina.

Com essa mudança de modelo de EaD, o total de materiais complementares (REAs), na área de Biologia, disponibilizados para os alunos nos anos de 2012 e 2013 foi de 1288 e 2044, respectivamente, representando um aumento de 63\%. Na Figura 4, observam-se os diferentes tipos de REAs disponibilizados para os alunos a partir de 2013. 


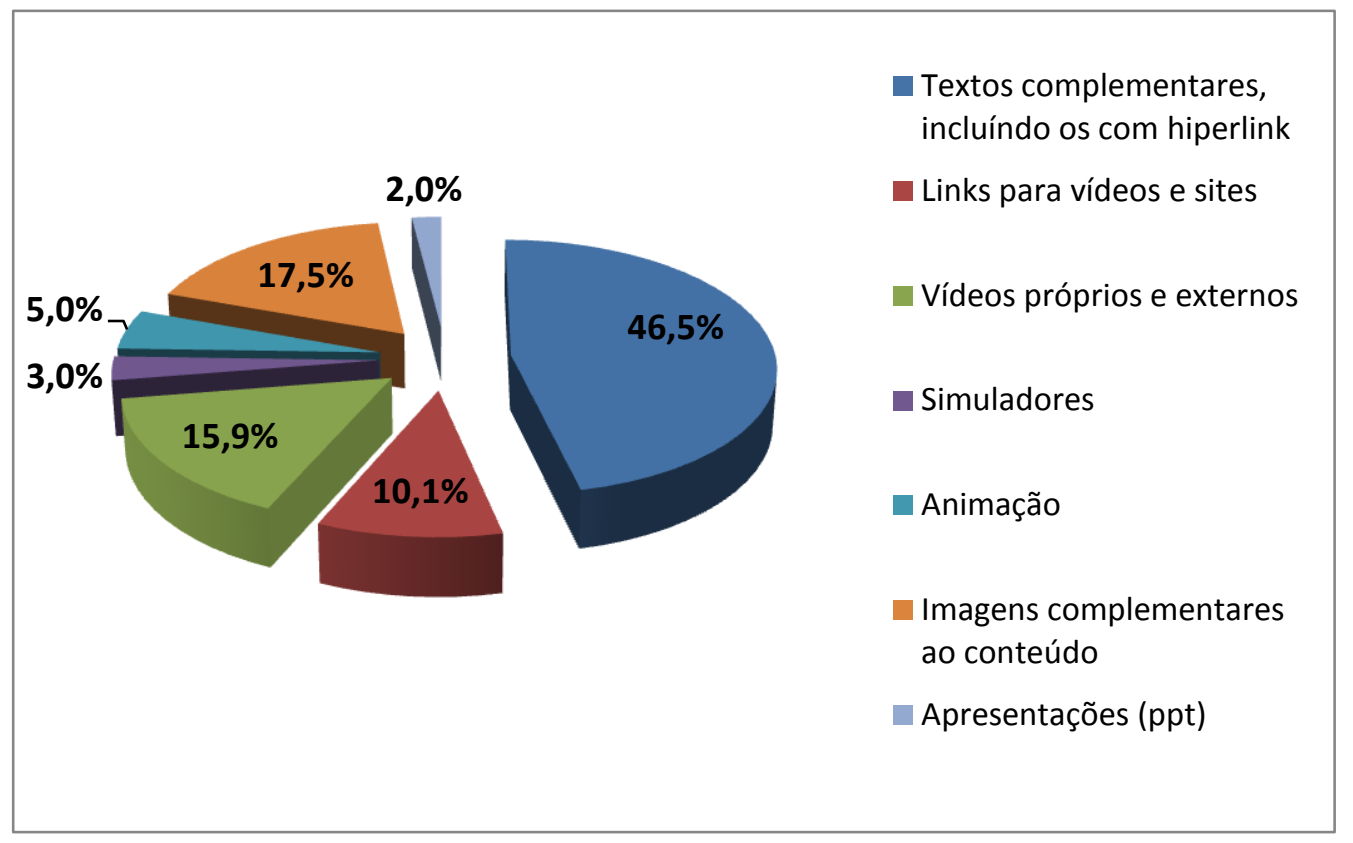

Figura 4 - Tipos de REAs disponibilizados para os alunos a partir de 2013, classificados em 7 categorias.

Na Figura 5, encontram-se os totais de materiais complementares (REAs) disponibilizados por disciplina, do curso de graduação em Ciências Biológicas, nos anos de 2012 e 2013. 


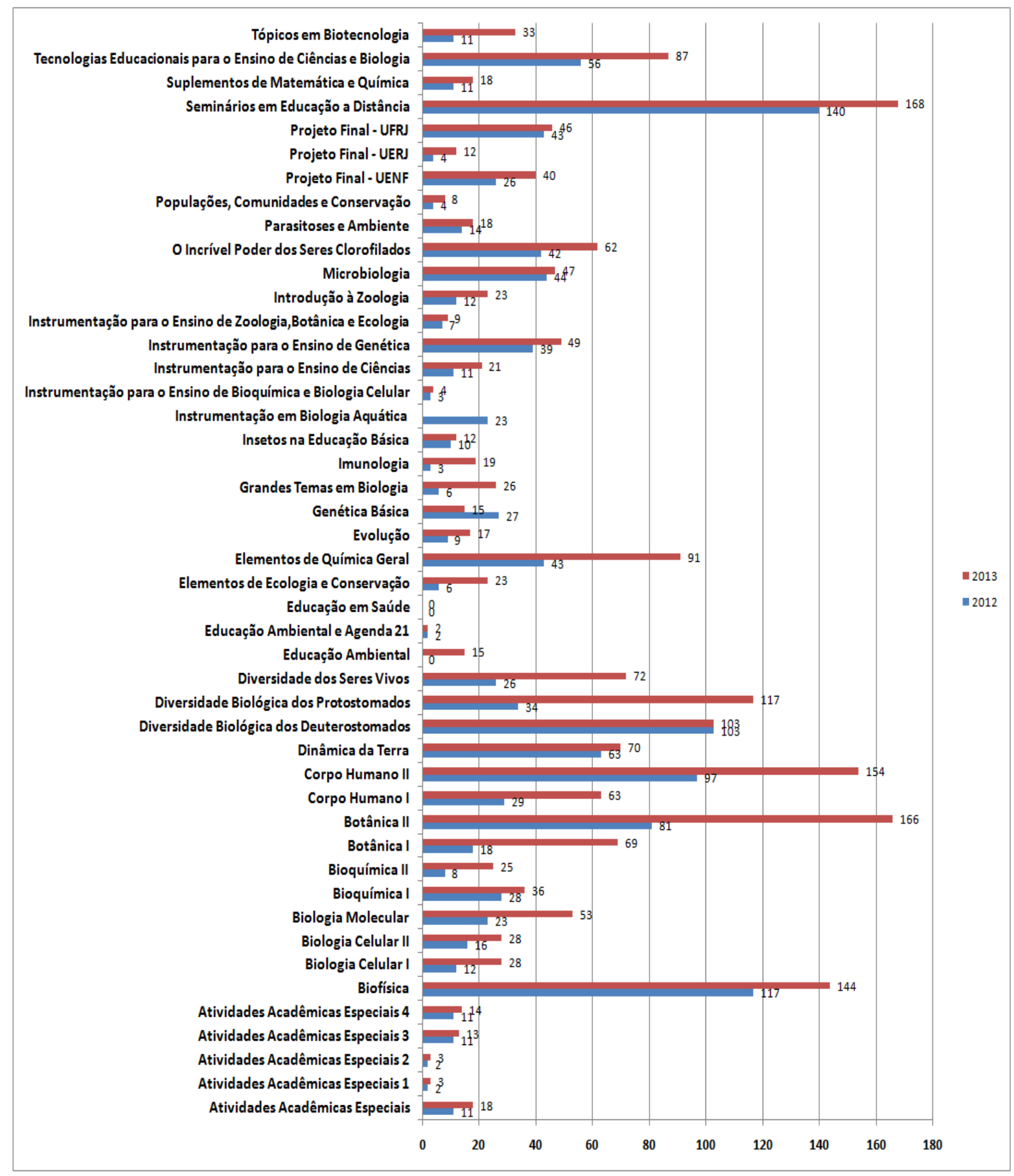

Figura 5 - Número total de REAs por disciplina no curso de Ciências Biológicas, nos anos de 2012 e 2013.

As webaulas são recursos multimídias muito interessantes e atraem a atenção dos alunos por possuírem imagens, cores e interatividade por meio de botõesalém de 
permitirem a contextualização do conteúdo teórico. Entretanto, essa produção demanda muito tempo e investimento, além de tirar a dinamicidade e autonomia do professor, tornando a sua produção pouco viável no modelo atual de uso da sala de aula do Consórcio Cederj.

Atualmente, os professores são responsáveis pela construção da sala de aula no Ambiente de Aprendizagem Virtual (AVA) Moodle, com total autonomia na inserção de recursos e textos complementares, além da colaboração de um Desenhista Instrucional (DI) e de Tutores de Apoio ao Professor (TAPs). Segundo Mattar (2012), com acesso cada vez mais amplo a recursos abertos e objetos de aprendizagem gratuitos e de qualidade, o professor de EaD tem em mãos o poder de inserir materiais adicionais (ou em substituição aos inicialmente previstos no curso) em função da sua turma e do ritmo de estudo. Siginorini et al. (2012) salientam a importância de o AVA permitir a autonomia do professor no gerenciamento do ambiente virtual.

Apesar da diminuição da produção de REAs pelo Departamento de Mídias Digitais do Consórcio Cederj, observa-se que a disponibilização de diferentes recursos multimídias nas disciplinas do curso de Ciências Biológicas vem crescendo, denotando um aumento de 63\% na utilização desses recursos pelos alunos do ano 2012 para o ano 2013. Isso porque os coordenadores de disciplina, juntamente com suporte de DI e TAPs, vêm selecionando cada vez mais REAs como recursos multimídias para essas disciplinas (Figura 4) e disponibilizando-os na plataforma Moodle e, mais recentemente, no E-book dinâmico do Consórrcio Cederj. Vale ressaltar que a implantação da plataforma Moodle favoreceu a maior utilização do AVA pelos professores e tutores, devido à facilidade de utilização das ferramentas de edição, possibilitando a autonomia dos docentes.

A inserção dos materiais complementares (REAs) foi dependente da disponibilidade do professor selecionar e inserir os recursos, na sala de aula, de sua respectiva disciplina no AVA. E, principalmente, devido ao perfil de cada disciplina com relação à necessidade de inserção de recursos multimídias relevantes e localizados na web de forma "abertos para uso", visando ao auxílio no processo de ensinoaprendizagem de suas disciplinas. 


\section{Considerações finais}

A mudança do modelo de produção e uso de REAs pelo curso de graduação a distância em Ciências Biológicas do Consórcio Cederj apresentou vantagens para os professores e alunos, pois houve um aumento significativo de REAs disponíveis na plataforma para visualização e estudo. O apoio à criteriosa seleção de recursos multimídias pelo professor junto com a produção de objetos de aprendizagem sob demanda pode ser a melhor opção para modelos de EaD que visem proporcionar mais autonomia e dinamicidade ao professor. Esse modelo pode ser enquadrado na classificação sugerida por Filatro (2008) como um modelo de desenho instrucional aberto e contextualizado.

Além dessa mudança na produção e uso de REAs, o Consórcio Cederj está em busca de alternativas tecnológicas de uso dinâmico de diversas mídias para benefício dos alunos. Por isso, em 2013, foi criado o Projeto-piloto "E-book Cederj" que consiste em disponibilizar os cadernos didáticos do Consórcio no formato digital para acesso via dispositivos móveis pelos alunos. Nesse E-book, os professores inseriram, de forma dinâmica, diversos recursos multimídias para serem acessados durante a navegação do aluno pelo livro digital. Os REAs incluídos no E-book consistem em links de diferentes tipos de materiais publicados na web como hipertextos, arquivos para download, animações e vídeos, imagens, além de links para fóruns e atividades na plataforma Moodle. Atualmente, o Consórcio Cederj possui 50 disciplinas com E-books já publicados totalizando 2117 recursos multimídias.

\section{Referências bibliográficas}

Benchimol, Marlene; Bernstein, Marianna Augusta Ferrari do Outeiro; Carvalho, Rodrigo Alcantara de \& Teixeira, Dirceu Esdras. (2010). Desenvolvimento de material multimídia no ensino de Biologia. Revista EAD em Foco, 1 (1), 99-158.

Carlini, Alda \& Tarcia, Rita Maria. (2010). 20\% a distância e agora?: orientações práticas para o uso de tecnologia de educação a distância no ensino presencial. São Paulo: Pearson Education do Brasil. 
Delgado, Laura; Haguenauer, Cristina; Moulin, Nelly; Melo, Fabiana \& Cordeiro, Francisco Filho. (2008). Uso da Plataforma Moodle no Suporte ao Ensino de Graduação Semi-Presencial. In: Congresso Internacional de Educaçâo a Distância, 14., 2008, Santos. Anais eletrônicos. Rio de Janeiro, UFRJ, 2008. Disponível em http://www.abed.org.br/congresso2008/tc/511200870511PM.pdf

Ferreira, Manuela Klanovicz; Horowitz, Zaida; Jouris, Adriana; Pavão, Caterina Groposo \& Costa, Janise Silva Borges da. (2013). Autoarquivamento de recursos educacionais abertos no lume. Workshop de Tecnologia da Informação e Comunicação das IFES, João Pessoa: UFPB. Disponível em https://www.lume.ufrgs.br/bitstream/handle/10183/72273/000883842.pdf?sequ ence $=1 \&$ locale $=$ pt BR

Filatro, Andrea. (2008). Design instrucional na prática. São Paulo: Pearson Education do Brasil.

Laaser, Wolfram; Rodrigues, Rosângela Schwarz \& Fachin, Gleisy Regina Bories. (2009). Educação a distância e recursos abertos. Revista Iberoamericana de Educación, 49(4).

Mattar, João. (2012). Tutoria e interação em educação à distância. São Paulo: Cengage Learning.

Okada, Alexandra \& Barros, Daniela Melaré Vieira. (2010). Ambientes virtuais de aprendizagem aberta: bases para uma nova tendência. Revista Digital de Tecnologias Cognitivas, 3, 20-35.

Signorini, A. V.; Ayres, A.; Seimetz, B. M.; Flores, L. S. \& Olchik, M. R. (2012). Aprendizagem ead em saúde: análise de uma vivência.: http://hdl.handle.net/10183/71160

Silva, Edna Lúcia da; Café, Lígia \& Catapan, Araci Hack. (2010). Os objetos educacionais, os metadados e os repositórios na sociedade da informação. Ci. Inf., Brasília, DF, 39 (3), 93-104. Disponível em http://www.scielo.br/scielo.php?pid=S0100$\underline{19652010000300008 \& \text { script }=\text { sci arttext }}$ 
Tarouco, Liane Margarida Rockenbach; Rodrigues, Alessandra Pereira \& Schmitt, Marcelo Augusto Rauh. (2013). Integração do MOODLE com Repositórios Abertos. Perspectivas em Ciência da Informação, 18(1), 66-85. Disponível em http://portaldeperiodicos.eci.ufmg.br/index.php/pci/article/view/1479/1106

Teixeira, António. (2012). Desconstruindo a universidade: Modelos universitários emergentes mais abertos, flexíveis e sustentáveis. Revista de Educación a distancia, 32, 1-13. Disponível em http://www.um.es/ead/red/32/teixeira.pdf

UNESCO. (2002). Unesco promotes new initiative for free educational resources on the Internet. Acesso em 20 agosto de 2014, disponível em http://www.unesco.org/education/news en/080702 free edu ress.shtml 